\title{
Cancer: improving early detection and prevention. A community practice randomised trial
}

\author{
Allen J Dietrich, Gerald T O'Connor, Adam Keller, Patricia A Carney, Drew Levy, \\ Fredrick S Whaley
}

\begin{abstract}
Objective-To test the impact of physician education and facilitator assisted office system interventions on cancer early detection and preventive services.

Design-A randomised trial of two interventions alone and in combination.

Setting and subjects - Physicians in 98 ambulatory care practices in the United States.

Interventions-The education intervention consisted of a day long physician meeting directed at improving knowledge, attitudes, and skills relevant to cancer prevention and early detection. The office system intervention consisted of assistance from a project facilitator in establishing routines for providing needed services. These routines included division of responsibilities for providing services among physicians and their staff and the use of medical record flow sheets.
\end{abstract}

Main outcome measures-The proportions of patients provided the cancer prevention and early detection services indicated annually according to the US National Cancer Institute.

Results-Based on cross sectional patient surveys, the office system intervention was associated with an increase in mammography, the recommendation to do breast self examination, clinical breast examination, faecal occult blood testing, advice to quit smoking, and the recommendation to decrease dietary fat. Education was associated only with an increase in mammography. Record review for a patient cohort confirmed cross sectional survey findings regarding the office system for mammography and faecal occult blood testing.

Conclusion-Community practices assisted by a facilitator in the development and implementation of an office system can substantially improve provision of cancer early detection and preventive services.

\section{Introduction}

The cancer detection and preventive services provided to many patients do not meet authoritative standards. A recent survey found that general practitioners from the Oxford region have positive attitudes towards prevention but only $64 \%$ routinely inquire about patients' smoking status and fewer inquire about other preventive services that are not related to symptoms. ${ }^{1}$ An American study found that only $53 \%$ of smokers frequently seen by a physician had been advised to quit.

Efforts to improve provision of preventive services in primary care have included professional education, ${ }^{2}$ performance feedback, ${ }^{56}$ administrative systems, ${ }^{7}$ and incentives." An innovative approach involving administrative systems has been developed in the Oxford area.$^{10} \mathrm{~A}$ facilitator from outside the practice works with the practice nurse and receptionist to implement a systematic approach to the prevention and early detection of cardiovascular disease. Dramatic increases resulted in weight and blood pressure measurements as well as in identification of smokers. " Almost three quarters of patients were found to require specific follow up or advice. ${ }^{12}$ In the first year after identification of hypertensive patients over $90 \%$ actually received follow up. ${ }^{13}$ This report describes a randomised trial that tested the impact of physician education and facilitator assisted office administrative system interventions on the cancer early detection and prevention services provided in practices in the United States.

\section{Subjects and methods}

The study followed a $2 \times 2$ factorial design. ${ }^{14}$ After collection of baseline data practices were randomly assigned to receive one of two interventions, both, or neither.

Office based family physicians and general internists in New Hampshire and Vermont were asked by telephone to participate. Physicians were excluded if they had been at their current practice site for less than 24 months, were based at a training site, or anticipated leaving their practice within the next year. The unit of randomisation was the medical practice as represented by one physician. In partnerships all physicians were assigned to the same study group and invited to participate in any interventions. However, evaluation data were collected only on the one physician whom the project had contacted first during recruitment.

Of 102 practices that agreed to participate, $98 \mathrm{co}-$ operated fully. Four physicians dropped out for such personal reasons as illness or unanticipated professional relocation, leaving 26 practices in the combined office system and education intervention group and 24 in each of the single intervention and control groups. Participating physicians were slightly younger than those who declined and were slightly less likely to be in solo practice.

A sample of patients provided data about physician performance. These patients were at least 42 years of age and had seen the physician at least once during the previous year. In addition, they were able to read, were accessible by telephone, and were not terminally ill. Age 42 was chosen because most early detection services for cancer apply to patients aged 40 and over and two additional years were allowed for a stable preintervention period. A service was considered to be performed if it was recommended or if the patient actually received the test, examination, or advice.

\section{EVALUATION END POINTS}

Interventions targeted gender appropriate services indicated annually according to the National Cancer

Dr Dietrich. 
Institute. ${ }^{15-17}$ These include advising patients to decrease fat and increase fibre intake, advising smokers to quit, clinical breast examination, mammography (age $\geqslant 50$ years), the recommendation to perform breast self examination, home faecal occult blood testing (age $\geqslant 50$ ), and digital rectal examination. Cervical cytology testing (if no history of hysterectomy) and sigmoidoscopy (age $\geqslant 50$ ) within the past year were also tracked. These services are indicated at up to three and five year intervals, respectively, according to the National Cancer Institute. ${ }^{1}$

\section{INTERVENTIONS}

The education intervention consisted of a day long meeting for physicians, offered three times in identical formats. Groups of 10 physicians discussed smoking cessation advice for 120 minutes and other services for 30 to 60 minutes each. Each group was led by an expert in the service who reviewed the recommendation of the National Cancer Institute and its rationale, then taught specific skills for optimal performance. A written syllabus was provided.

The office system intervention consisted of assistance from a project facilitator in the design and implementation of office routines that support provision of cancer early detection and preventive services. Facilitators were guests in the practices and provided consultation, not patient care. Six facilitators received extensive training and used standard presentation materials. Facilitators assisted practices in performing an initial audit to assess the status of preventive care. In addition, they helped the practice physician(s) and staff to share responsibility for providing needed services and to integrate preventive care flow sheets and other tools into practice operations. Facilitators visited each practice three times over three months and provided additional assistance as needed.

With assistance from the facilitator, office system practices designed and implemented preventive care flow sheets in patients' records. A typical flow sheet listed preventive services in one column with additional columns to record the dates that services were provided. Tools that practices could select included external identifiers for smokers' charts, health education posters and brochures, and patient held health diaries. ${ }^{18}$ Practices implemented only those tools that met their specific perceived needs. None of the tools or flow sheets were computer based. In a typical division of responsibility the practice nurse assessed a patient's need for services by reviewing the flow sheet and asking the patient. If services were indicated the nurse advised the patient and notified the physician. The physician typically provided actual clinical examinations and counselling. Reception staff scheduled needed services obtained outside the practice such as mammography.

Each intervention required about eight hours of physician time. Physicians in the combined intervention group therefore devoted 16 hours to attending project intervention sessions. The office system intervention involved practice staff in six hours of meetings at the practice.

\section{EVALUATION INSTRUMENTS}

Data were collected by mailed patient exit questionnaires and medical record reviews. These instruments were extensively pilot tested in non-participating practices. Data sources did not distinguish services provided for diagnosis or treatment from those provided for prevention or early detection.

Patient exit questionnaires inquired about services received during the previous 12 months. Two different cross sectional surveys of 20-30 patients from each physician were completed. This first occurred before study group assignment. The second occurred
12-14 months after interventions began. At the end of randomly selected days project staff called practice receptionists to request names, addresses, and telephone numbers of all eligible patients seen within the previous 48 hours. Surveys were then mailed to patients the following day.

Project staff reviewed the medical records of the cohort of consenting patients who returned the pre-intervention patient exit questionnaire. Records were audited once at least 12 months after interventions began. The review covered two time periods. The pre-intervention period included each patient's index visit and the 364 days before it. The intervention period extended from the day after the index visit through the date of the record review. This period was at least 365 days for each patient.

\section{ANALYSIS OF PATIENT CROSS SECTIONAL SURVEY DATA}

Each of the two cross sectional surveys determined the proportion of appropriate patients from each practice receiving services during the prior 12 months. Mean proportions for each service from the practices in each study group were compared by using two factor analysis of covariance. The arcsin transformed proportions from the post-intervention survey were the dependent variables. The independent variables were the education and the office system interventions as well as an interaction term between them..$^{19}$ The arcsin transformed proportions based on the pre-intervention survey were used as covariates. Statistical significance was defined as $\mathrm{p}<0 \cdot 05$.

A priori sample size calculations ${ }^{21}$ assumed an $\alpha$ statistic of $0 \cdot 05$, a $\beta$ statistic of $0 \cdot 20$, and baseline rates of service as determined by a regional pilot study. These indicated that 25 practices per study group would be sufficient to detect a $30 \%$ improvement in most services. The exception was sigmoidoscopy, for which a $50 \%$ improvement could be detected.

\section{ANALYSIS OF RECORD REVIEW COHORT DATA}

Record review addressed mammography and home faecal occult blood testing, which are documented by formal reports in the record and indicated annually according to the National Cancer Institute. Other annual services were not addressed by record review.

For each service and each study group the incidence density for the intervention period was calculated. The total number of each needed service provided to age and gender appropriate patients during the intervention period was the numerator. The total number of days that these same patients were due for that service was the denominator. The number of days that a patient was due for a service depended on the date the service was last received. If a patient received a service during the pre-intervention period that patient was not considered due for it again for 365 days.

The incidence density for each intervention group was then divided by the incidence density for the control group during the same period to give a rate ratio for each service. For example, if 100 appropriate patients from the practices in one intervention group received a service during 10000 patient days that the service was due and 50 appropriate patients received the same service from control group practices during the same number of patient days the rate ratio would be $2 \cdot 0$. Ninety five per cent confidence intervals were also calculated."

\section{Results}

\section{PHYSICIAN AND PATIENT CHARACTERISTICS}

Characteristics of study group physicians are summarised in table I. All physicians assigned to the education intervention attended. All physicians 
assigned to the office system intervention cooperated with facilitator assistance.

In the cross sectional surveys done before and after the interventions began 2436 and 2595 patients respectively completed the patient exit questionnaire, representing $93 \%$ and $91 \%$ of those eligible at each interval. In these surveys $61 \cdot 2 \%$ and $61 \cdot 8 \%$ of respondents were female, $66.6 \%$ and $69.4 \%$ were between 42 and 69 years of age, $28 \cdot 1 \%$ and $30 \cdot 2 \%$ had not graduated from high school, $17 \cdot 1 \%$ and $19 \cdot 2 \%$ were current smokers, and $40 \cdot 7 \%$ and $45 \cdot 4 \%$ had been regular patients of their designated physician for at least five years. During the 12 months before each survey patients averaged 5.6 and 5.9 visits. As determined by age, gender, history of hysterectomy, and current smoking status the number of patients eligible for specific services during each survey was at least 446 for smoking cessation advice, over 2400 for digital rectal examination and dietary advice, and at least 1000 for other services.

TABLE I-Characteristics of participating physicians by study group ${ }^{\star}$

\begin{tabular}{lcccc}
\hline & \multicolumn{4}{c}{ Physician study group } \\
\cline { 2 - 5 } Characteristics & Control & Education only & Office system only & Office system/education \\
\hline No & 24 & 24 & 24 & 26 \\
Current mean age (years) & $42 \cdot 0$ & $40 \cdot 5$ & $41 \cdot 3$ & $43 \cdot 0$ \\
Male gender & $22(92)$ & $24(100)$ & $21(88)$ & $25(96)$ \\
Specialty: & $7(29)$ & $9(38)$ & $10(42)$ & $7(27)$ \\
$\quad$ Internal medicine & $17(71)$ & $15(63)$ & $14(58)$ & $19(73)$ \\
$\quad$ Family medicine & $22(92)$ & $22(92)$ & $17(71)$ & $21(81)$ \\
Board certified & $12(50)$ & $11(46)$ & $13(54)$ & $12(46)$ \\
Type of practice: & $12(50)$ & $13(54)$ & $11(46)$ & $14(54)$ \\
$\quad$ Solo & & & &
\end{tabular}

$\star$ Except where stated otherwise, results are expressed as numbers (percentages) of physicians. Differences were not significant $(p<0.05)$ as determined by analysis of variance, $\chi^{2}$ test, and Fisher's exact test.

TABLE II-Proportions of eligible female patients who reported receiving services during previous year at baseline and 12 months after interventions began ${ }^{\star}$

\begin{tabular}{|c|c|c|c|c|c|}
\hline \multirow[b]{2}{*}{ Service (indication) } & \multirow[b]{2}{*}{ Time period } & \multicolumn{4}{|c|}{ Physician study group } \\
\hline & & Control & $\begin{array}{l}\text { Education } \\
\text { only }\end{array}$ & $\begin{array}{l}\text { Office system } \\
\text { only }\end{array}$ & $\begin{array}{l}\text { Office system/ } \\
\text { education }\end{array}$ \\
\hline Mammogram (age $\geqslant 50)$ & $\left\{\begin{array}{l}\text { Baseline } \\
12 \text { Months }\end{array}\right.$ & $\begin{array}{l}0.58 \\
0.57\end{array}$ & $\begin{array}{l}0.53 \\
0.71 \dagger\end{array}$ & $\begin{array}{l}0.59 \\
0.77 \dagger\end{array}$ & $\begin{array}{l}0.57 \\
0.78 \dagger\end{array}$ \\
\hline Clinical breast examination & $\left\{\begin{array}{l}\text { Baseline } \\
12 \text { Months }\end{array}\right.$ & $\begin{array}{l}0.69 \\
0.65\end{array}$ & $\begin{array}{l}0.67 \\
0.71\end{array}$ & $\begin{array}{l}0 \cdot 70 \\
0 \cdot 79 \ddagger\end{array}$ & $\begin{array}{l}0.69 \\
0.80 \ddagger\end{array}$ \\
\hline Breast self examination recommendation & $\left\{\begin{array}{l}\text { Baseline } \\
12 \text { Months }\end{array}\right.$ & $\begin{array}{l}0.57 \\
0.54\end{array}$ & $\begin{array}{l}0.52 \\
0.56\end{array}$ & $\begin{array}{l}0 \cdot 60 \\
0 \cdot 70 \ddagger\end{array}$ & $\begin{array}{l}0.56 \\
0.67 \ddagger\end{array}$ \\
\hline Cervical cytology (no hysterectomy) & $\left\{\begin{array}{l}\text { Baseline } \\
12 \text { Months }\end{array}\right.$ & $\begin{array}{l}0 \cdot 63 \\
0 \cdot 61\end{array}$ & $\begin{array}{l}0.61 \\
0.63\end{array}$ & $\begin{array}{l}0.58 \\
0.71\end{array}$ & $\begin{array}{l}0.61 \\
0.65\end{array}$ \\
\hline
\end{tabular}

*Proportions given are means for practices in each study group. Twelve month results by study group were compared by using analysis of covariance on arcsin transformed proportions with baseline results as covariates. Standard errors ranged from 0.03 to 0.05 .

$t \mathrm{p}<0.01$ for office system only $v$ control and education only $v$ contro

$\ddagger \mathrm{p}<0.05$ for office system only $v$ no office system.

TABLE III-Proportions of eligible patients who reported receiving services during previous year at baseline and 12 months after interventions began

\begin{tabular}{|c|c|c|c|c|c|}
\hline \multirow[b]{2}{*}{ Service (indication) } & \multirow[b]{2}{*}{ Time period } & \multicolumn{4}{|c|}{ Physician study group } \\
\hline & & Control & $\begin{array}{l}\text { Education } \\
\text { only }\end{array}$ & $\begin{array}{l}\text { Office system } \\
\text { only }\end{array}$ & $\begin{array}{c}\text { Office system/ } \\
\text { education }\end{array}$ \\
\hline Stool occult blood (age $\geqslant 50$ ) & $\left\{\begin{array}{l}\text { Baseline } \\
12 \text { Months }\end{array}\right.$ & $\begin{array}{l}0 \cdot 45 \\
0 \cdot 46\end{array}$ & $\begin{array}{l}0 \cdot 48 \\
0 \cdot 54\end{array}$ & $\begin{array}{l}0.48 \\
0.62 \dagger\end{array}$ & $\begin{array}{l}0.43 \\
0.61 \dagger\end{array}$ \\
\hline Digital rectal examination & $\left\{\begin{array}{l}\text { Baseline } \\
12 \text { Months }\end{array}\right.$ & $\begin{array}{l}0.54 \\
0.57\end{array}$ & $\begin{array}{l}0.60 \\
0.60\end{array}$ & $\begin{array}{l}0.59 \\
0.66\end{array}$ & $\begin{array}{l}0.58 \\
0.63\end{array}$ \\
\hline Sigmoidoscopy (age $\geqslant 50$ ) & $\left\{\begin{array}{l}\text { Baseline } \\
12 \text { Months }\end{array}\right.$ & $\begin{array}{l}0 \cdot 20 \\
0 \cdot 24\end{array}$ & $\begin{array}{l}0 \cdot 28 \\
0 \cdot 30\end{array}$ & $\begin{array}{l}0 \cdot 25 \\
0 \cdot 31\end{array}$ & $\begin{array}{l}0 \cdot 24 \\
0 \cdot 27\end{array}$ \\
\hline Reduce fat recommendation & $\left\{\begin{array}{l}\text { Baseline } \\
12 \text { Months }\end{array}\right.$ & $\begin{array}{l}0.49 \\
0.47\end{array}$ & $\begin{array}{l}0 \cdot 43 \\
0 \cdot 48\end{array}$ & $\begin{array}{l}0.49 \\
0.56 \neq\end{array}$ & $\begin{array}{l}0.47 \\
0.51\end{array}$ \\
\hline Increase fibre recommendation & $\left\{\begin{array}{l}\text { Baseline } \\
12 \text { Months }\end{array}\right.$ & $\begin{array}{l}0.34 \\
0.38\end{array}$ & $\begin{array}{l}0.32 \\
0.38\end{array}$ & $\begin{array}{l}0 \cdot 40 \\
0 \cdot 48\end{array}$ & $\begin{array}{l}0 \cdot 34 \\
0 \cdot 41\end{array}$ \\
\hline Advise smokers to quit & $\left\{\begin{array}{l}\text { Baseline } \\
12 \text { Months }\end{array}\right.$ & $\begin{array}{l}0.73 \\
0.67\end{array}$ & $\begin{array}{l}0.79 \\
0.73\end{array}$ & $\begin{array}{l}0.83 \\
0.84 \ddagger\end{array}$ & $\begin{array}{l}0 \cdot 78 \\
0.80\end{array}$ \\
\hline
\end{tabular}

* Results at 12 months were compared by using analysis of covariance on arcsin transformed proportions with baseline results as covariates. Standard errors ranged from 0.02 to 0.08 .

$t p<0.05$ for office system only $v$ no office system.

$\ddagger \mathrm{p}<0.05$ for office system only $v$ control.
PHYSICIAN PERFORMANCE VERSUS RECOMMENDATIONS

Provision of services appropriate exclusively for women is summarised in table II as determined by baseline and 12 month cross sectional surveys. For the three services indicated annually one or both of the interventions had a statistically significant positive effect. The proportion of women receiving mammography was higher among those whose physicians were assigned to either the education only $(p=0.0085)$ or the office system only interventions $(p=0.0023)$ versus those whose physicians were controls. The combination of two interventions was no better than either one alone. If their physician was assigned to the office system intervention patients also received more clinical breast examinations $(p=0.037)$ and recommendations to perform breast self examination $(p=0 \cdot 049)$ than those whose physicians were not so assigned. The proportion of women provided cervical cytology during the previous year was higher 12 months after the intervention in practices assigned the office system, but this did not reach statistical significance.

Provision of services indicated regardless of gender of patients is summarised in table III. For three of the five indicated annually the office system intervention had a statistically significant positive effect. More patients of physicians assigned to the office system intervention were advised to do home faecal occult blood tests $(p=0.010)$ than those whose physicians were not, regardless of whether the physician received the education intervention. A higher proportion of patients cared for by physicians receiving the office system intervention in the absence of the education intervention were provided recommendations to decrease dietary fat $(p=0.018)$ than those cared for by physicians who did not receive it. More recommendations to quit smoking were provided for smokers cared for by physicians receiving the office system intervention in the absence of the education intervention $(p=0.017)$. The proportion of patients for whom sigmoidoscopy was provided during the previous year was higher at 12 months in practices receiving an intervention, but this did not reach statistical significance.

Record reviews for a cohort of 2032 patients were used to corroborate the cross sectional survey findings for mammography and home faecal occult blood testing. Rate ratios comparing performance of mammography for office system only and office system and education study groups with controls were 1.54 and $1 \cdot 60$, respectively, with $95 \%$ confidence intervals of 1.09 to $2 \cdot 17$ and $1 \cdot 19$ to $2 \cdot 15$. Rate ratios comparing performance of faecal occult blood tests of office system only and office system and education study groups with controls were 1.44 and 1.45 , respectively, with $95 \%$ confidence intervals of 1.03 to 2.02 and 1.05 to 1.99 . The rate ratio comparing performance of education only practices with controls was 1.04 for mammography and 1.13 for faecal occult blood testing, but $95 \%$ confidence intervals for both included $1 \cdot 0$.

Combining patient exit questionnaire and record review data allowed determination of how often mammography or sigmoidoscopy was provided for the first time ever to patients after the interventions began. For control group women (aged $\geqslant 50$ ) who had indicated in the pre-intervention patient survey that they had never had a mammogram $(n=98), 23 \cdot 5 \%$ were subsequently served for the first time after the interventions began. Among similar patients of practices assigned to the education intervention only $(\mathrm{n}=72)$ and office system only $(\mathrm{n}=97), 29 \cdot 2 \%$ and $46.4 \%$, respectively, were served for the first time after the interventions began. Among similar patients of practices receiving both the education and office system intervention $(n=103), 49 \cdot 5 \%$ were subsequently served. This issue was also explored for 
sigmoidoscopy, which was provided for the first time ever after interventions began to $5 \cdot 5 \%$ of 235 patients (aged $\geqslant 50$ ) in the control group, $14.4 \%$ of 181 patients in the education only group, $15.8 \%$ of 240 in the office system only group, and $20.0 \%$ of 270 in the combined intervention group.

\section{Discussion}

These results provide evidence that facilitator assistance in implementing an office system can increase provision of most cancer prevention and early detection services. Practices assigned to physician education increased mammography only. Of the services indicated annually, only digital rectal examination and the dietary fibre recommendation were not significantly higher in the 12 month survey for at least one of the office system study groups. Sigmoidoscopy and cervical cytology proportions were higher in office system practices, but this also did not reach statistical significance. However, the full effect of an intervention on services indicated less than annually may require more than one year to detect. These findings demonstrate the feasibility and impact of implementing the Oxford facilitator model in clinical areas other than cardiovascular disease prevention and in the United States as well as the United Kingdom. This evidence suggests that whatever the specific preventive and early detection services a facilitator can help improve performance.

Why did counselling to decrease dietary fat and to quit smoking increase for the office system only group but not the combined intervention group? Education sessions addressed controversies behind specific recommendations of the National Cancer Institute, but the office system intervention did not. Perhaps exploring the rationale behind the recommendations raised doubts about some services as well as increasing knowledge and skills.

Why was mammography the only service to increase with education? During the group discussions that were part of the education meeting it was clear that physicians considered many factors in recommending mammography. Particularly prominent was the physician's perception of the patient's interest and ability to pay. At the education meeting physicians were told that if women were advised to obtain a mammogram by their physicians, then allowed to decide for themselves, many would comply. This advice was the subject of substantial discussion and led most physicians to agree to "try it," and has since been supported by data from the National Cancer Institute Breast Cancer Screening Consortium. ${ }^{23}$

It is of note that among control and education only practices the proportion of smokers advised to quit fell by 0.06 between the pre-intervention and 12 month surveys. This may reflect the impact of quit smoking initiatives directed at physicians by the National Cancer Institute ${ }^{1:}$ and the American Academy of Family Physicians ${ }^{2+}$ during the pre-intervention year that were not as active subsequently. Practices assigned the office system only improved performance slightly from the baseline survey but were performing significantly better at 12 months than the other practices.

One caveat is in order. Study outcome data cannot distinguish the impact of the various components of the office system. Was the flow sheet more influential than the process of negotiating and sharing responsibility among all staff? Was one flow sheet design more efficacious than another? Rather than a limitation of the study, flexibility in developing an office system with the assistance of a facilitator may have allowed diverse practices to address their unique needs, motivated them to implement the system, and enabled them to maintain it.
The more successful intervention was the facilitator initiated office system. In future applications of these results practices could be assisted in implementing office systems by intermediary organisations that could employ facilitators, such as area or regional health services as in the Oxford region, physician specialty societies, or anticancer groups. The use of these intermediaries and their staff as external consultants to assist primary care practices in the design of office systems that support provision of preventive services is currently being tested in the United States through the National Cancer Institute's prescribe for health initiative. ${ }^{25}$

In conclusion, community practices assigned to implement an office system with assistance from a facilitator provided more cancer early detection and preventive services. As developed in the Oxford area facilitators represent an innovative resource for improving provision of cancer early detection and preventive services and perhaps other services as well. Future initiatives to improve practice performance in prevention and other clinical areas should consider involvement of practice staff as well as physicians and use of facilitators to improve practice organisation.

This research was supported by grants R01CA46075 and CA23108 from the National Cancer Institute. We are indebted to the following participating physicians, their associates, and their office staffs: D Adamson, D Albright, $\mathrm{R}$ Backus, S Bayer, D Beaufait, E Benoit, J Berman, $H$ Bower, H Braese, D Brumley, T Cantlin, J Capobianco, T Capron, J Carmola, C Carrier, B Carroll, R Chaney, D Clark, R Cochran, D Coddaire, D Coolidge, N Couture, D Cross, K Crowley, F Dibble, J Dick, G Diederich, P Doane, E Doherty-Fuller, R Douglass, S Elgert, J Elsbree, D Eubank, J Evans, R Ezerman, R Felgate, J Ferguson, J Fitzgerald, G Fjeld, R Friedman, P Friedrichs, P Friend, R Gagne, P Glowa, P Gustavson, M Hamilton, W Hart, F Hartman, F Hayes, W Hernandez, D Hobbs, S Horton, J Hughes, R Hutchins, G Idelkope, W Jones, S Kaitz, J Kaminski, D King, K Lammers, C LaRocca, A Law, P Lens,

P Leonard-Schwartz, J Leppman, E Levis, T Lewis, D Loveman, D MacDonald, D Melville, D Merrihew, T Naumann, E Oidtmann, M Parker, M Peake, R Penney, D Phillips, C Pierce, M Polifka, L Pressman, L Ramey, R Ramey, R Robinson, B Rosen, R Rosenberg, S Roth, J Rowe, R Rufsvold, D Russo, R Salmon, A Schneider T Shafer, K Singer, K Smith, S Smith, G Sobelson, H Southall, D Stafford, P Stebbins, M Stein, M Sterling, B Stern, P Teem, J Thomas, W Walsh, G Waring, C Ward, W Weiss, R Wilson, C Wolcott, A Yuskaitis, R Zelazo, T Ziobrowski.

In addition, Eugene $C$ Nelson and Jeannette Simmons were instrumental in the conceptulisation of this project; physicians of the Dartmouth Primary Care Cooperative Information Network assisted with recruitment; Peter Anderson, Richard Belch, Paul Frame, Louis Hochheiser, Laird Myers, James Pease, and Mark Quirk assisted in providing the education intervention; Larry Dickey provided patient held diaries; James Barrett assisted with evaluation; Charlotte Woodruff, Deborah Berger, Cecelia Gaffney, Susan Gilbert, Tanya Heidenreich, Jeanne Landgraf, Deborah Lawrence, and Romani Thaler assisted with project implementation; Suzanne Haynes and William Mayers, our project officers, were solid in their encouragement and support; and Susan Scown and Susanna Reed assisted in the development of this manuscript.

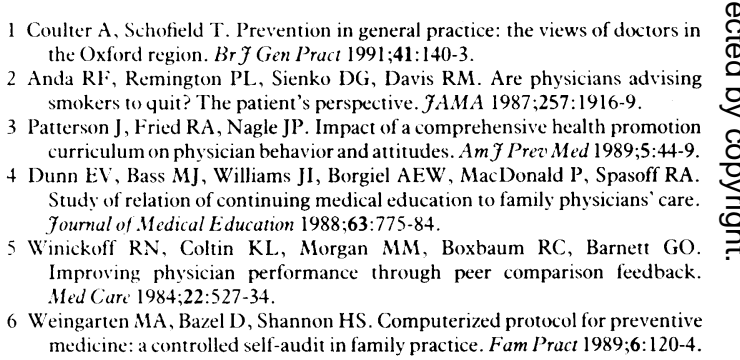
7 Davidson RA, Fletcher SW, Retchin S, Duh S. A nurse-initiated reminder

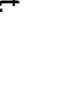


system for the periodic health examinution: implementation and evaluation. trch Intern. Hed 1984;144:2167-70.

8 .McPhee SJ, Bird JA, Fordham D, Rodnick JE, Osborn E. Promoting cancer prevention activities by primary care physicians: results of a randomized, controlled a

9 Chomet J, Chomet J. Cervical screening in general practice: a "new" scenario. BMf 1990;300:1504-6.

10 Fullard E, Fowler G, Gray M. Facilitating prevention in primary care. B.Mf 1984:289:1585-7.

11 Fullard E, Fowler G, Gray M. Promoting prevention in primary care: controlled trial of low technology, low cost approach. BMJ 1987;294 1080-2.

12 Mant D, McKinlay C, Fuller A, Randall T, Fullard E, Muir J. Three vea follow up of patients with raised blood pressure identified at health checks in general practice. BMF 1989;298:1360-2.

13 Imperial Cancer Research Fund OXCHECK Study Group. Prevalence of risk factors for heart disease in OXCHECK trial: implications for screening in primary care. BMF 1991;302:1057-60.

1t Srampfer MU, Buring JE Willet W, Rosner B, Eberlein $\mathrm{K}$, Hennekens $\mathrm{CH}$ The $2 \times 2$ factorial design: its application to a randomized trial of aspirin and The $2 \times 2$ factorial design: its application to a rando

15 National Cancer Institute. Working guidelines for early cancer detection: rationale and supporting evidence to decrease mortality. Bethesda, Maryland: NCI, 1987.
16 Butrum RR, Clifford CK, Lanza E. NCI dietary guidelines: rationale. Am $\mathcal{F}$ Clin Nutr 1988;48:888-95.

17 Glynn TJ, Manley MW. How to help your patients stop smoking. Bethesda, Maryland: National Institutes of Health, 1989. Publication No 89-2064

18 Dickey LL, Petitti D. Assessment of a patient-held minirecord for adult health maintenance. f Fam Pract 1990;31:431-8.

19 Neter J, Wasserman W, Kutnor MH. Applied linear statistical models. 2nd ed. Homewood, Illinois: Richard Irwin, 1985

20 Draper N, Smith H. Applied regression analysis. 2nd ed. New York, NY: John Wiley and Sons, 1981.

21 Donner A, Birkett N, Buck C. Randomization by cluster. Sample size requirements and analysis. Am $\mathcal{F}$ Epidemiol 1981;114:906-14.

22 Kleinbaum DG, Kupper LL, Morgenstern H. Epidemiologic research: principles and quantitative methods. Belmont, California: Lifetime Learning Publications, 1982:351.

23 National Cancer Institute Breast Cancer Screening Consortium. Screening mammography: a missed clinical oportunity? fAMA 1990;264:54-8.

24 American Academy of Family Physicians. Stop smoking kit. Kansas City, Missouri: AAFP, 1987.

25 Prevention program being developed aimed at primary care providers. Cancer Lett $1988 ; 14: 4$

(Accepted 12 December 1991)

\title{
Randomised trial of three approaches for marketing smoking cessation programmes to Australian general practitioners
}

\author{
Jill Cockburn, Denise Ruth, Chris Silagy, Malcolm Dobbin, Yolande Reid, Michelle Scollo, \\ Lucio Naccarella
}

Centre for Behavioural Research in Cancer, Carlton, Victoria, Australia Jill Cockburn, PHD, senior behavioural scientist

Lucio Naccarella, BSC, evaluation officer

\section{Monash University,}

Monash, Australia

Denise Ruth, FFAFPHM, senior lecturer,

department of community medicine

Chris Silagy, FRACGP, senior research fellow, departments of social and preventive medicine and community medicine Malcolm Dobbin, PHD, postgraduate student-master of public health, department of social and preventive medicine

\section{Victorian Smoking and}

Health Program,

Melbourne, Australia

Yolande Reid, ASSOC DIP COM $\mathrm{WK}$, coordinator, health professional programme Michelle Scollo, BSC, executive director

Correspondence to: Dr Jill

Cockburn, Centre for Behavioural Research in Cancer, Anti-Cancer Council of Victoria, Carlton, Victoria, Australia 3053.

BMF 1992;304:691-4
Abstract

Objective-To compare three approaches for marketing a quit smoking intervention kit to general practitioners.

Design-Randomised trial of $(a)$ personal delivery and presentation by an educational facilitator with a follow up visit six weeks later; $(b)$ delivery to the receptionist by a friendly volunteer courier with a follow up phone call six weeks later, or $(c)$ postal delivery with a follow up letter six weeks later.

Setting-Melbourne, Australia.

Subjects-264 randomly selected general practitioners.

Data collection-A research assistant visited each doctor four months after delivery and measured use of components of the kit. A questionnaire measuring perceptions of aspects of the kit and its delivery was completed by doctors. Costs of each approach were calculated.

Results-Doctors receiving the educational facilitator approach were significantly more likely than those receiving the other two approaches to have seen the kit, to rate the method of delivery as engendering motivation to try the kit, to have used one of the "intensive intervention" components from the kit, to report that they found the kit less complicated, and to report greater knowledge of how to use the kit. There were no significant differences in use of "minimal intervention" components of the kit, ratings of overall acceptability of delivery, perceptions of cultural and structural barriers to using the kit, and ratings of the overall acceptability of the kit. The cost of the educational facilitator approach (\$A142/doctor) was 24 times that of the mailed approach. The volunteer courier approach (\$A14) was twice the cost of the mailed approach.

Conclusion-Educational facilitators and volunteer couriers do not seem to be cost effective strategies for distributing smoking interventions.

\section{Introduction}

Given the large proportion of the population seen by general practitioners, ${ }^{1-3}$ if general practitioners were routinely to advise their smoking patients to quit even quite low rates of success would result in a substantial number of new former smokers.. ${ }^{23}$ Several general practice based smoking intervention programmes are efficacious in controlled research settings, ${ }^{+6}$ but general practitioners tend not routinely to use these in actual practice. ${ }^{7}$ From a public health viewpoint general practice based smoking interventions are not reaching their maximum potential. It was this observation, together with the lack of success of a distribution procedure for their own smoking intervention programme, which led Fowler and colleagues to conclude, "The amount of energy expended in the production of [smoking] interventions must be at least equalled in marketing and dissemination." "

In Australia the Victorian Smoking and Health Program has recently faced the challenge of finding a suitable mechanism for marketing and distributing a newly developed smoking intervention programme in a way that would encourage its routine use in general practice. There were few published data on how this could best be achieved. Fowler et al distributed their brief intervention as an insert in the $B M A$ News Review and found that few general practitioners could recall the key components of their programme. ${ }^{8}$ Other programmes have relied on attendance at introductory seminars, often with disappointing results..$^{910}$

Experiences with marketing other products to general practitioners have largely centred on pharmaceuticals. Pharmaceutical representatives seem to be effective for promoting pharmaceuticals, " and academic "detailers" or "educational facilitators" have been found to be both effective and cost effective for promoting rational prescribing among general practitioners. ${ }^{\prime 2}$ There is no reported use of this approach for marketing smoking interventions to general practitioners.

We have conducted this trial to examine the effectiveness and cost effectiveness of different strategies for distributing and marketing smoking interventions to general practitioners.

\section{Subjects and methods}

A sample of general practitioners from the Melbourne metropolitan region was randomly selected from the Victorian Medical Board register. These general practitioners were randomly allocated to receive one of 